\title{
A Child with Multiple Inflammatory Syndrome in Children, Stroke and Cardiac Insufficiency
}

\author{
Seyedeh Narjes Ahmadizadeh ${ }^{1}$, Fariba Shirvani ${ }^{2,}{ }^{*}$, Seyedeh Masumeh Hashemi ${ }^{1}$, Azita Behzad ${ }^{1}$, Zahra \\ Pournasiri (iD ${ }^{3}$, Maryam Alemzadeh ${ }^{1}$ and Masoumeh Mohkam (iD) ${ }^{3}$ \\ ${ }^{1}$ Pediatric Intensive Care Departmant, Mofid Children Hospital, Shahid Beheshti University of Medical Sciences, Tehran, Iran \\ ${ }^{2}$ Pediatric Infections Research Center (PIRC), Research Institute for Children's Health (RICH), Shahid Beheshti University of Medical Sciences, Tehran, Iran \\ ${ }^{3}$ Pediatric Nephrology Research Center, Research Institute for Children's Health, Shahid Beheshti University of Medical Sciences, Tehran, Iran \\ "Corresponding author: Pediatric Infections Research Center (PIRC), Research Institute for Children's Health (RICH), Shahid Beheshti University of Medical Sciences, Tehran, \\ Iran. Email: shirvanifariba@rocketmail.com
}

Received 2021 May 08; Revised 2021 September 07; Accepted 2021 October 16.

\begin{abstract}
Multiple inflammatory syndrome in children (MIS-C) is a multisystem inflammatory disease following COVID-19 in children. This disease occurs a few weeks after COVID-19. A child with this condition develops a cytokine release cascade that results in organ damage. The involved organs include the heart, lungs, brain, gastrointestinal tract, and central nervous system. Fever is present in all patients and Kawasaki-like symptoms are one of the common features in these children. In this article, we introduce a child with MIS-C who has skin, gastrointestinal, neurological, and renal symptoms and has been hospitalized in the PICU.
\end{abstract}

Keywords: Multiple Inflammatory Syndrome Children, COVID-19, Children

\section{Introduction}

Multisystem inflammatory syndrome in children(MISC) is a condition with inflammation in different parts of body, including brain, kidney, lungs, eyes, heart, skin, and gastrointestinal organs (1). These children may have fever and symptoms, including vomiting, diarrhea, rash, neck pain, conjunctivitis, and neurologic symptoms. Many children with MIS-C are PCR- or antibody-positive for COVID-19. The Center for Disease Control and Prevention (CDC) defines MIS-C features as follows: (1) the age under 21 years old; (2) having laboratory evidence of inflammation and fever; (3) having evidence of severe illness requiring hospitalization; and (4) more than two organ involvement in the absence of other diagnoses, and evidence of SARS-CoV2 exposure or infection (2). There are reports of acute heart failure in pediatric patients with MIS-C due to SARS-COV-2 infection (3). Brain ischemic stroke is a rare complication of COVID-19 in patients with MIS-C $(4,5)$. We report a 7-yearold boy with MIS-C and heart failure, and brain ischemic stroke. The reason for introducing this patient is the early onset of chronic renal replacement therapy (CRRT) and its positive effects on the patient's treatment, report of treatment of heart failure in the patient with levosimendan, and presenting stroke in the patient's brain.

\section{Case Presentation}

A 7-year-old overweight boy [body mass index $(\mathrm{BMI})=$ 25.6; weight $=37 \mathrm{~kg}$; height $=120 \mathrm{~cm}$ ] was admitted to our hospital PICU, Mofid Children Hospital, which is an Academic, Governmental, Referral, Educational Children Hospital. The patient had a history of fever, nausea, vomiting, cough, and constipation for one week who was visited by different physicians. There was a positive history of contact with a COVID-19 positive parent. He was prescribed several types of antibiotics, anti-nausea, probiotics, and analgesics that were ineffective. A Foley catheter was placed in another facility, and the possibility of bladder rupture was considered due to lack of proper insertion. On admission, he was ill and pale, GCS $=10$, and there was severe abdominal pain. $\mathrm{T}=38.1, \mathrm{BP}=90 / 60, \mathrm{PR}=96 / \mathrm{min}$, $\mathrm{RR}=23 / \mathrm{min}, \mathrm{O}_{2}$ Sat (Saturation) at room air was $94 \%$. On physical examination, he had no respiratory distress, and respiratory sounds were normal. Hepatomegaly was evident $3 \mathrm{~cm}$ below costal margin and splenomegaly $2 \mathrm{~cm}$ below costal margin, and there was generalized abdominal tenderness. Rebound tenderness was not detectable because of patient lack of cooperation. On echocardiography ejection fraction (EF) was $10 \%$. Subsequently, it was found that the reason for the decrease in saturation was low EF. Few bilateral ground-glass opacities were found on 
chest CT-scan (Figure 1). In chest X-ray, pleural effusion was noted on the right side, and there was Para hilar haziness (Figure 2). Twelve days after admission, he developed left side hemiparesis. In brain CT-scan without contrast, gyral hyperdensity in right temporoparietal segment was suggestive of laminar cortical necrosis, and hypodensity was noted in the right temporoparietal zone due to ischemia (Figure 3). Brain CT angiography reported no detectable occlusion, stenosis, aneurysm formation, and abnormal displacement along with the brain arterial structures. Brain MRI without contrast and diffuse-weighted imaging showed evidence of gyriform T1 hyperintensities in right temporoparietal region due to cortical necrosis associated with microhemorrhage. There were abnormal signal areas in right cerebral hemisphere, mainly involving cortex and subcortical white matter in the territory of right Mid Cerebral artery (MCA. Ascites fluid analysis revealed $\mathrm{Glu}=283 \mathrm{mg} / \mathrm{dL}, \mathrm{Lymph}=80 \%$, poly $=20 \%$ pro $=$ $3,200 \mathrm{mg} / \mathrm{dL}, \mathrm{WBC}=200, \mathrm{RBC}=300, \mathrm{LDH}$ fluid $=699 \mathrm{mg} / \mathrm{dL}$. Ascites culture was enterococcus resistant to Ampicillin, Ciprofloxacin, Vancomycin. Vancomycin trough concentration was $20.6 \mathrm{mcg} / \mathrm{mL}$. CSF Analysis showed $\mathrm{Glu}=63$ $\mathrm{mg} / \mathrm{dL}$, Pro $=18 \mathrm{mg} / \mathrm{dL}, \mathrm{WBC}=0 \mathrm{RBC}=3,600$. Moreover, CSF PCR was negative for HSV1/2, VZV, EBV, Enterovirus, CMV, JC virus, Influenza virus1/2, and COVID-19.

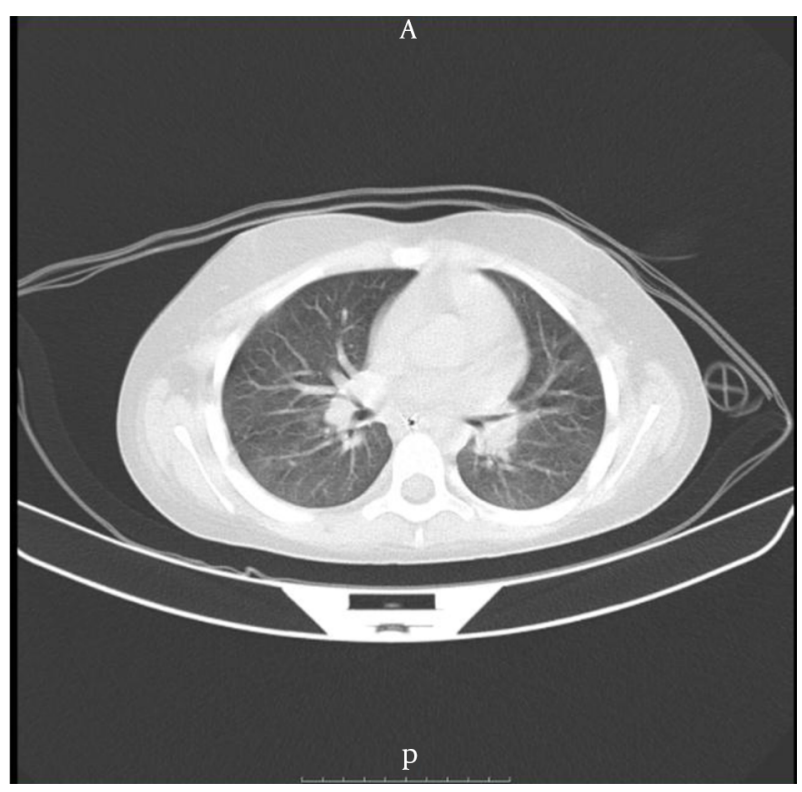

Figure 1. Bilateral ground-glass opacities on chest CT-scan

In $\mathrm{CBC}, \mathrm{WBC}=19,100 / \mu \mathrm{L}, \mathrm{Neut}=90 \%, \mathrm{Lym}=8 \%, \mathrm{Hb}=6$ $\mathrm{mg} / \mathrm{dl}, \mathrm{RDW}=16.3 \%, \mathrm{PLT}=223,000 / \mu \mathrm{L}$. Other laboratory results are shown in Table1. SARS-CoV2 PCR and Influenza PCR were negative.

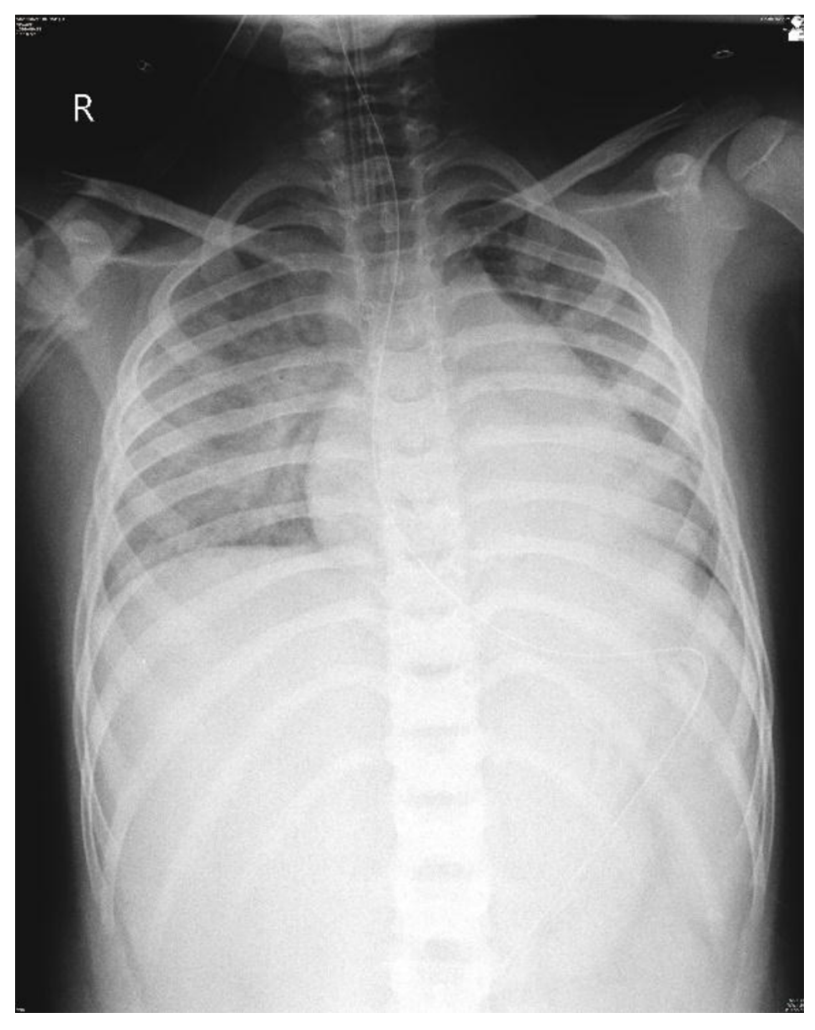

Figure 2. Pleural effusion on right side and Para hilar haziness

Rheumatologic consultation recommended HLA-B5, CANCA, PANCA, Anti-CCP, RF, FANA, Anti-Cardiolipin (IgG and IgM), AntiB2Glycoprotein (IgG and IgM), and Antismith. All rheumatologic test results are shown in Table 2. Stroke panel including anti thrombin $3=129 \%(80-120)$, protein $C=118 \%(70-140)$, protein $S=71 \%(55-160)$, serum homocystein $=10.9 \mu \mathrm{mol} / \mathrm{L}(5-15)$, factor 5 leiden $=3.15 \mathrm{sec}$ (2.18 - 3.38), factor 8, 9,10,12, 13 were within normal range.

Immunologic consultation recommended IgG, IgM, IgE and IgA which were within normal range. IL-6 = 9.8 $\mathrm{pg} / \mathrm{mL}$ (up to 5.9 ), CD3 $=37.9 \%$ (35 - 78\%), CD19 $=43.6 \%$ (3 $14 \%), \mathrm{CD} 20=41.5 \%(3-15 \%), \mathrm{CD} 16=1.89, \mathrm{CD} 4=18.3 \%(22-62 \%)$, $\mathrm{CD} 8=17.9 \%$ (12 - 36\%), CD4/CD8 $=1.02(1-3), \mathrm{CD} 56=4.24 \%$. $\mathrm{NBT}=100 \%$, LTT for DT and Candida decreased a little and was normal for PHA and BCG. No immunologic syndrome was detected.

His peritoneal tap revealed exudative fluid. Bladder rupture was raised by respected surgeon colleagues, and after the rejection of bladder rupture, appendectomy was performed after seeing inflamed appendix in laparotomy. The pathologic result of appendectomy was vermiform appendix with lymphoid hyperplasia. The patient was intubated in the operating room and was not extubated due to 


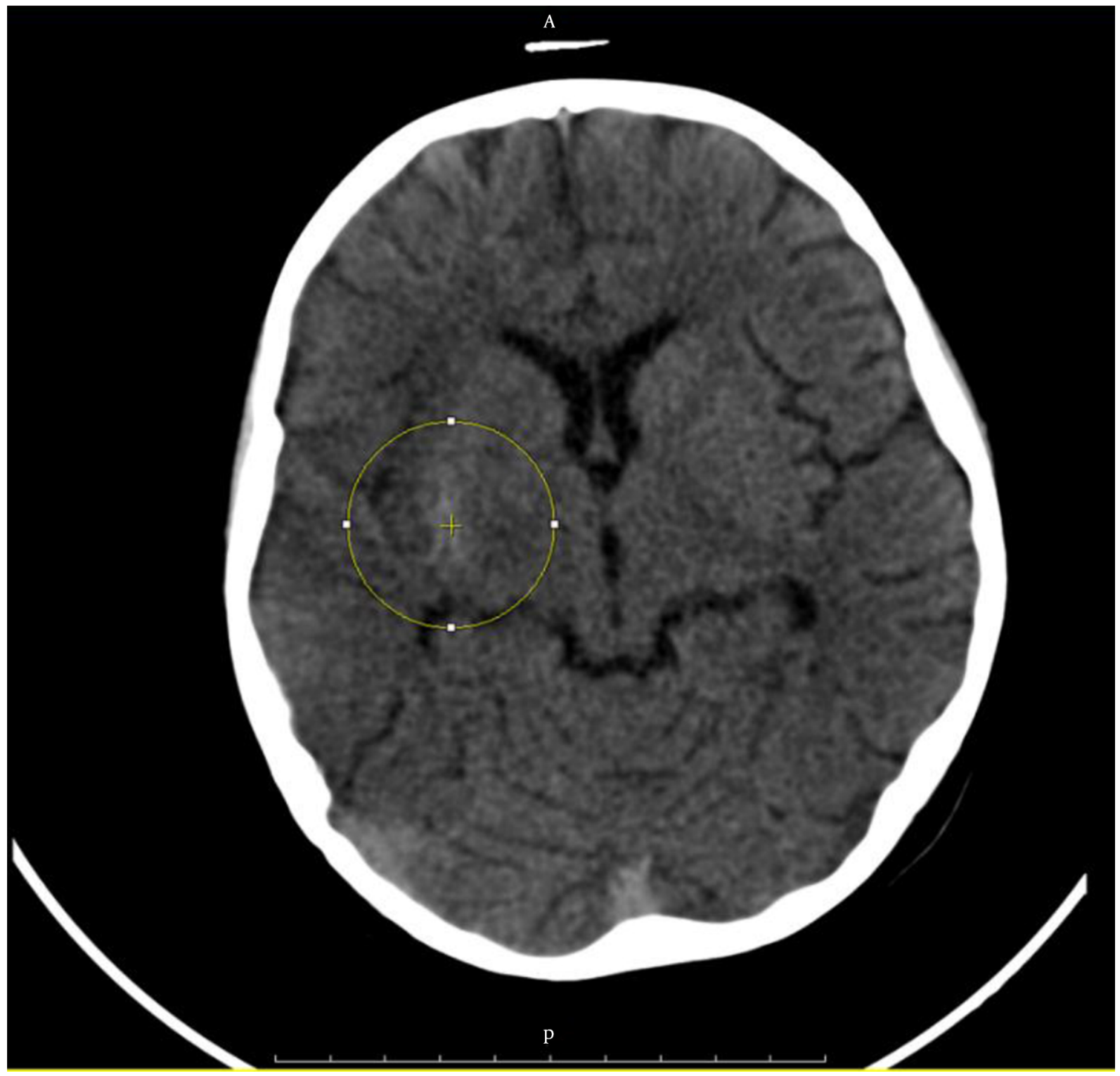

Figure 3. Gyral hyperdensity on right temporoparietal segment suggestive of laminar cortical necrosis and hypodensity on right temporoparietal zone due to ischemia.

a continued decreased level of oxygen saturation.

Two days after admission, continuous renal replacement therapy (CRRT) was started and continued for $48 \mathrm{hr}$. At that time, despite the lack of dehydration, creatinine began to increase, which decreased with early CRRT to 0.8. Urine analysis showed hematuria 10 days after admission, which was improved gradually. Left lower limb edema occurred after ten days of admission, and arterial and venous color Doppler of lower limb was normal in the left side, and edema disappeared gradually.

Meropenem 1 gr q 8 hr, vancomycin 370 mg q 6 hr, acyclovir: $370 \mathrm{mg} \mathrm{q} 8 \mathrm{hr}$ and discontinued two days after negative l p, enoxaparin: $18 \mathrm{mg}$ Sc q 12hr, norepinephrine: $0.1 \mathrm{macro} / \mathrm{kg} / \mathrm{min}$, epinephrine: $0.1 \mathrm{macro} / \mathrm{kg} / \mathrm{min}$, lasix: $0.05 \mathrm{mg} / \mathrm{kg} / \mathrm{hr}$, milrinone: $50 \mathrm{mcg} / \mathrm{kg}$ loading dose by IV push over 10 - 60 minutes, then 0.25 - $0.75 \mathrm{mcg} / \mathrm{kg} / \mathrm{min} \mathrm{IV}$, carvedilol $25 \mathrm{mg} / \mathrm{BD}$, and captopril 0.3 - $0.5 \mathrm{mg} / \mathrm{kg} / \mathrm{dose} / \mathrm{BD}$ were started. All of them were manufactured in Iran, levosimendan dose was $0.1 \mu \mathrm{g}(\mu \mathrm{g} / \mathrm{kg} / \mathrm{min}$ for $36 \mathrm{hr}$ manufactured by Ukraine. In spite of complete use of cardiotropic agents, EF was low, and levosimendan $0.1 \mu \mathrm{g} / \mathrm{kg} / \mathrm{min}$ (manufactured by Ukraine) was started, and he responded dra- 


\begin{tabular}{|c|c|c|}
\hline Laboratory Exams & Results & Normal Range \\
\hline AST (SGOT) & $57 \mathrm{U} / \mathrm{L}$ & $<37$ \\
\hline ALT(SGPT) & $116 \mathrm{U} / \mathrm{L}$ & $<41$ \\
\hline LDH & $1,255 \mathrm{U} / \mathrm{L}$ & $<580$ girl,$<746$ boy \\
\hline T Troponin & $0.072 \mathrm{ng} / \mathrm{mL}$ & $\begin{array}{c}\text { Low risk } \leq 0.03, \text { Mod risk }= \\
0.03-0.1 \text {, high risk } \geq 0.1\end{array}$ \\
\hline Troponin & 0.313 & $<0.29$ \\
\hline $\begin{array}{l}\text { Creatinine } \\
\text { Phosphokinase }\end{array}$ & $212 \mathrm{U} / \mathrm{L}$ & $0-195$ \\
\hline CPK-MB & $44.3 \mathrm{U} / \mathrm{L}$ & $0.5-25$ \\
\hline Uric acid & $0.9 \mathrm{mg} / \mathrm{dL}$ & $3-6.4$ \\
\hline CRP & 180 & $<10$ \\
\hline ESR & $55 / \mathrm{hr}$ & $5-30$ \\
\hline Amylase & $55 \mathrm{u} / \mathrm{L}$ & 30 to 110 \\
\hline Creatinine & $1.5 \mathrm{mg} / \mathrm{dL}$ & $\begin{array}{c}\text { Children ages } 3 \text { to } 18 \text { years. } \\
0.3 \text { to } 0.7 \mathrm{mg} / \mathrm{dL}\end{array}$ \\
\hline $\mathrm{Na}$ & 135 meq/l & $135-148$ \\
\hline $\mathbf{K}$ & $3.5 \mathrm{meq} / \mathrm{l}$ & $3.5-5.3$ \\
\hline PCT & $20 \mathrm{ng} / \mathrm{mL}$ & $\begin{array}{l}\text { More than } 2 \text { is seen in } \\
\text { severe sepsis }\end{array}$ \\
\hline Ferritin & $18,900 \mathrm{ng} / \mathrm{mL}$ & $6.7-177$ \\
\hline Fibrinogen & $372 \mathrm{mg} / \mathrm{dL}$ & $200-400 \mathrm{mg} / \mathrm{dL}$ \\
\hline Cholesterol & $231 \mathrm{mg} / \mathrm{dL}$ & $<200$ \\
\hline Triglyceride & $238 \mathrm{mg} / \mathrm{dL}$ & $<200$ \\
\hline Total pro & $5.5 \mathrm{gr} / \mathrm{dL}$ & $5.7-8$ \\
\hline Alb & $3.2 \mathrm{gr} / \mathrm{dL}$ & 3.4 to $5.4 \mathrm{~g} / \mathrm{dL}$ \\
\hline $\mathbf{C a}$ & $8.2 \mathrm{mg} / \mathrm{dL}$ & $8.6-10.3$ \\
\hline Phosphorus & $2.6 \mathrm{mg} / \mathrm{dL}$ & $3-7$ \\
\hline C1 & $107 \mathrm{meq} / \mathrm{l}$ & $98-110$ \\
\hline C3 & $137 \mathrm{mg} / \mathrm{dL}$ & $90-180$ \\
\hline C4 & $37 \mathrm{mg} / \mathrm{dL}$ & $10-40$ \\
\hline COVID-19 IgG-Ab & $1.81 \mathrm{IU} / \mathrm{mL}$ & $\begin{array}{c}\text { Neg } \leq 0.9, \text { borderline }= \\
0.9-1.1, \text { Pos } \geq 1.1\end{array}$ \\
\hline COVID-19 IgM-ab & $0.09 \mathrm{IU} / \mathrm{mL}$ & $\begin{array}{c}\mathrm{Neg} \leq 0.9, \text { borderline }= \\
0.9-1.1, \text { Pos }>1.1\end{array}$ \\
\hline
\end{tabular}

matically with increase in EF to 55\%. The patient suffered from skin rash during admission, and intravenous immunoglobulin (IVIG) and Methylprednisolone pulse therapy were started. Anticoagulant prophylaxis was changed to therapeutic dose after hemiparesis development. Informed consent was obtained from the family, and they consented to report their child's illness. The pediatric intensivist, pediatric infectious diseases subspecialist, pediatric immunologist, pediatric rheumatologist, and pediatric cardiologist participated as teamwork in the manage-

\begin{tabular}{lcc}
\hline Table 2. Reumatologic Panel & & \\
\hline Laboratory Exams & Results & Normal Range \\
\hline ANA & $\mathrm{Neg}$ & \\
\hline Anti-DNA & $5.3 \mathrm{IU} / \mathrm{mL}$ & Pos $>25$ \\
\hline Anti-cardiolipine IgG & $1.26 \mathrm{U} / \mathrm{mL}$ & Pos $>18$ \\
\hline Anti-cardiolipin IgM & $5.7 \mathrm{MPL} \mathrm{U} / \mathrm{mL}$ & Positive low $=13-14.9$ \\
\hline Anti-smooth muscle Ab & $\mathrm{Neg}$ & \\
\hline SSA/Ro IgG & $2.3 \mathrm{U} / \mathrm{mL}$ & Pos $>18$ \\
\hline SSB/La IgG & $1.5 \mathrm{U} / \mathrm{mL}$ & Pos $>18$ \\
\hline ANCA/IFA & $\mathrm{Neg}$ & \\
\hline Anti-MPO & $<2 \mathrm{Ru} / \mathrm{mL}$ & Pos $>20$ \\
\hline Anti-PR3 & $2.8 \mathrm{U} / \mathrm{mL}$ & Pos $>18$ \\
\hline Anti-smith & $80 \mathrm{EU} / \mathrm{mL}$ & Pos $>25$ \\
\hline Anti-Beta2 glyciprotein IgG & $<1 \mathrm{U} / \mathrm{mL}$ & Pos $>18$ \\
\hline Anti-Beta2 glyciprotein IgM & $0.9 \mathrm{U} / \mathrm{mL}$ & Pos $>18$ \\
\hline Anti-CCP & $14 \mathrm{U} / \mathrm{mL}$ & Pos $>18$ \\
\hline Rheumatoid factor $(\mathbf{R F})$ & $\mathrm{Neg}$ & \\
\hline HLA-B5 & $\mathrm{Neg}$ & \\
\hline HLA-B27 & $\mathrm{Neg}$ & \\
\hline HLA-B51 & $\mathrm{Neg}$ & \\
\hline
\end{tabular}

ment of this patient. The patient was gradually improved and discharged after 20 days' admission. He was well at subsequent follow-up visits.

\section{Discussion}

The patient that we studied had MIS-C on the basis of diagnostic criteria. He had fever and high inflammatory markers, including LDH, Ferritin, ESR, CRP, and organ involvement, including CNS, Skin, kidney, and Heart. He also had positive serologic markers (6). The patient was initially admitted with the possibility of appendicitis and had visceral involvement with exudative ascites. Our patient underwent surgery, but he had no appendicitis or intraabdominal surgery problems. In a study in Italy in 2021, among 1,010 children with MIS-C, $4.2 \%$ had an acute abdominal diagnosis, and 3.8\% had surgery, of which $89.7 \%$ had a final diagnosis of appendicitis (7). Creatinine increased, which was improved with supportive therapies such as CRRT. The prevalence of acute kidney injury (AKI) in COVID-19 patients is approximately $27.8 \%$. Continuous renal replacement therapy (CRRT) is an important therapeutic modality in patients with COVID-19 and AKI. Absolute indications for initiating CRRT are overt uremia and hyperkalemia, but the optimal timing of therapy is the subject of debate (8). A 15-year-old girl with renal failure and MIS-C 
was hospitalized in the United States and completely recovered. Moreover, BUN and creatinine increased but CRRT deferred in the setting of dehydration and intravenous therapy resulted in significant improvement. She also had skin rash and had antibodies to COVID-19 similar to our patient (9). The optimum time for CRRT is $16.5 \mathrm{hr}$ of AKI and mortality is lower than the interval of 28,60 , and $90 \mathrm{hr}(10)$. In our patient, early initiation of CRRT could prevent the progression of renal involvement and increase the patient's chances of survival. In a multisystem study in Europe, 286 children from 55 centers were included. The most common cardiovascular involvements were pericardial effusion, arrhythmias, coronary artery problems, and reduced left ventricular EF, which occurred in one-half of patients (11). Our patient had decreased cardiac EF, and cardiotonic drugs were used for his treatment without significant improvement. There was a dramatic response to levosimendan. This drug is indicated in the short-term treatment of heart failure with inadequate effect of conventional therapy. Levosimendan opens sarcolemmal and mitochondrial potassium-ATP channels. It improves cardiac function with no increase in oxygen consumption. The effect is not attenuated by concomitant use of beta-blockers (12). Our patient did not respond to epinephrine, norepinephrine, and milrinone, and dobutamine. The last drug, levosimendan, was effective, and the patient was treated successfully. Levosimendan is a vasodilator alongside the effect of inotrope. Its consumption is spreading in children (13). Its use has not been reported in MIS-C patients. Our case experienced left side hemiparesis during the course of admission, and the cause was reported as an ischemic problem in the right temporoparietal zone of the cerebral cortex. In a case series report from Chile 2021, the neurologic complications were epilepsy exacerbation, anosmia, ageusia, headache, Guillain-Barre syndrome, encephalopathy, and demyelinating events (14). A case of stroke firstly resulted in brain infarction and death in a child with COVID-19 (15). The pathophysiology of acute cerebral ischemia in COVID19 are para-infectious and immune-mediated, and hypercoagulable state and endothelial indentation (15). The virus interferes with the function of ACE2 in cerebrovascular self-regulation, while reports of thrombosis, especially in the higher ages, have been reported (16). Our patient developed cortical ischemia due to the involvement of the MCA artery. Fortunately, the paralysis of the left side of the body was improved during hospitalization and left no permanent complication. In our patient, despite a complete immunological examination, no clear immunodeficiency was detected. Cases of associated immunodeficiency are less common in patients with MIS-C (17). All rheumatologic tests in our patient were negative except for anti-smith antibody. This antibody has high specificity for SLE. It is ele- vated in $30 \%$ of SLE and $8 \%$ of mixed connective tissue disease (MCTD) cases. Smith antigens are part of extractable nuclear antigens (18). We found no correlation between MIS-C and SLE in the review of literature, and our patient did not show any symptoms of SLE. The anti-smith specificity of SLE antibodies decreases with the observation of positive cases in lung cancer (19). Our patient was an MIS$C$ case that his vital organs of the brain, heart, and kidney were involved, that all were improved with the treatment. He had no problems at subsequent visits, and his tests were scheduled to be checked regularly.

\subsection{Conclusion}

Multiple inflammatory syndrome in children (MIS-C) is improved if diagnosed and treated early. Performing continuous renal replacement therapy (CRRT) in patients with kidney involvement in MIS-C can be lifesaving and must be done before the inflammatory process is stabilized. The decision to treat should be made on time and completely because the inflammatory process can be very destructive in patients with MIS-C. Levosimendan is a drug that can be used in patients with cardiac insufficiency if they do not respond to other drugs.

\section{Footnotes}

Authors' Contribution: SN.A and SM.H prepared the case; A.B, Z.P, and M.A prepared the review of literature and F.SH and M.M edited the article.

Conflict of Interests: There is no conflict of interest.

Funding/Support: There is no funding support.

Informed Consent: We took the informed consent from his parents.

\section{References}

1. Center for Disease Control and Prevention. Multisystem Inflammatory Syndrome (MIS). Atlanta, Georgia: Center for Disease Control and Prevention; 2021, [cited 2021]. Available from: https:/www.cdc.gov/mis/ index.html.

2. Center for Disease Control and Prevention. Information for Healthcare Providers about Multisystem Inflammatory Syndrome in Children (MIS-C). Atlanta, Georgia: Center for Disease Control and Prevention; 2020, [cited 9th Oct 2020]. Available from: https://www.cdc.gov/mis $/ \mathrm{mis}-$ c/hcp/index.html?CDC_AA_refVal=https\%3A\%2F\%2Fwww.cdc. gov\%2Fmis $\% 2$ Fhcp $\% 2$ Findex.html.

3. Belhadjer Z, Meot M, Bajolle F, Khraiche D, Legendre A, Abakka S, et al. Acute Heart Failure in Multisystem Inflammatory Syndrome in Children in the Context of Global SARS-CoV-2 Pandemic. Circulation. 2020;142(5):429-36. doi: 10.1161/CIRCULATIONAHA.120.048360. [PubMed: 32418446]. 
4. Tiwari L, Shekhar S, Bansal A, Kumar S. COVID-19 associated arterial ischaemic stroke and multisystem inflammatory syndrome in children: A case report. Lancet Child Adolesc Health. 2021;5(1):88-90. doi: 10.1016/S2352-4642(20)30314-X. [PubMed: 33340468]. [PubMed Central: PMC7832826].

5. Riphagen S, Gomez X, Gonzalez-Martinez C, Wilkinson N, Theocharis P. Hyperinflammatory shock in children during COVID-19 pandemic. Lancet. 2020;395(10237):1607-8. doi: 10.1016/S0140-6736(20)31094-1. [PubMed: 32386565]. [PubMed Central: PMC7204765].

6. Dunn JJ, Brown CA. What is multisystem inflammatory syndrome (MIS) in children (MIS-C) and how is it diagnosed? New York, USA: Medscape; 2021, [cited 2021]. Available from: https://www.medscape.com/ answers/2500138-201123/what-is-multisystem-inflammatorysyndrome-mis-in-children-mis-c-and-how-is-it-diagnosed.

7. Yock-Corrales A, Lenzi J, Ulloa-Gutierrez R, Gomez-Vargas J, AntunezMontes OY, Rios Aida JA, et al. Acute Abdomen and Appendicitis in 1010 Pediatric Patients With COVID-19 or MIS-C: A Multinational Experience from Latin America. Pediatr Infect Dis J. 2021;40(10):e364-9. doi:10.1097/INF.0000000000003240.[PubMed:34260501].[PubMed Central: PMC8443421].

8. Palevsky PM. Renal replacement therapy in acute kidney injury. Adv Chronic Kidney Dis. 2013;20(1):76-84. doi: 10.1053/j.ackd.2012.09.004. [PubMed: 23265599]. [PubMed Central: PMC3531877].

9. Lee M, Hilado M, Sotelo S, Opas LM, Im DD. Acute Kidney Injury in Multisystem Inflammatory Syndrome in Children (MIS-C): A Case Report. SN Compr Clin Med. 2020:1-4. doi: 10.1007/s42399-020-00647-9. [PubMed: 33251482]. [PubMed Central: PMC7679784].

10. Yoon BR, Leem AY, Park MS, Kim YS, Chung KS. Optimal timing of initiating continuous renal replacement therapy in septic shock patients with acute kidney injury. Sci Rep. 2019;9(1):11981. doi: 10.1038/s41598019-48418-4. [PubMed: 31427640]. [PubMed Central: PMC6700095].

11. Valverde I, Singh Y, Sanchez-de-Toledo J, Theocharis P, Chikermane A, Di Filippo S, et al. Acute Cardiovascular Manifestations in 286 Children With Multisystem Inflammatory Syndrome Associated With COVID-19 Infection in Europe. Circulation. 2021;143(1):21-32. doi:
10.1161/CIRCULATIONAHA.120.050065. [PubMed: 33166189].

12. Nieminen MS, Fruhwald S, Heunks LM, Suominen PK, Gordon AC, Kivikko M, et al. Levosimendan: current data, clinical use and future development. Heart Lung Vessel.2013;5(4):227-45. [PubMed: 24364017]. [PubMed Central: PMC3868185].

13. Seguela PE, Tafer N, Thambo JB, Mauriat P. [Use of levosimendan in children]. Arch Pediatr. 2016;23(8):848-56. French. doi: 10.1016/j.arcped.2016.05.002. [PubMed: 27369103].

14. Sandoval F, Julio K, Mendez G, Valderas C, Echeverria AC, Perinetti MJ, et al. Neurologic Features Associated With SARS-CoV-2 Infection in Children: A Case Series Report. J Child Neurol. 2021;36(10):853-66. doi: 10.1177/0883073821989164. [PubMed: 33646895].

15. Kangin M, Talay MN, Kavak S, Alparslan C, Sayinbatur B, Akar A, et al. Brain death in a child as a result of COVID-19-associated acute stroke: The first case. J Paediatr Child Health. 2021. doi: 10.1111/jpc.15421. [PubMed: 33710694]. [PubMed Central: PMC8251168].

16. Lin JE, Asfour A, Sewell TB, Hooe B, Pryce P, Earley C, et al. Neurological issues in children with COVID-19. Neurosci Lett. 2021;743:135567. doi: 10.1016/j.neulet.2020.135567. [PubMed: 33352286]. [PubMed Central: PMC7831718].

17. Diorio C, Henrickson SE, Vella LA, McNerney KO, Chase J, Burudpakdee $\mathrm{C}$, et al. Multisystem inflammatory syndrome in children and COVID-19 are distinct presentations of SARS-CoV-2. J Clin Invest. 2020;130(11):5967-75. doi: 10.1172/JCI140970. [PubMed: 32730233]. [PubMed Central: PMC7598044].

18. Patel NM. Anti-Smith Antibody. New York, USA: Medscape; 2020, [cited 2021]. Available from: https://emedicine.medscape.com/ article/2086751-overview\#: :text=Anti\%2DSmith\%20antibody\% 20has\%20low, \%2Dtissue \%20disease \%20(MCTD).\&text=Anti\% 2DSmith\%20antibody\%20is\%20more, than $\% 20$ in $\% 20$ whites $\%$ 20with\%20SLE.

19. Timlin H, Machireddy K, Shiroky J, Ravi S, Haque U. Anti-Smith Antibody Positivity Without Lupus in the Setting of Lung Cancer. Cureus. 2020;12(5). e8298. doi: 10.7759/cureus.8298. [PubMed: 32601571]. [PubMed Central: PMC7317121]. 